Supporting Information

Efficient and Sustainable Removal of Magnesium from Brines for Lithium/Magnesium Separation Using Binary Extractants

Zheng Li, * Jonas Mercken, Xiaohua Li, Sofía Riaño and Koen Binnemans

Total number of pages: 23 (S1-S23)

Total number of figures: 17 (Figure S1-S17)

Total number of tables: 1 (Table S1) 


\section{Characterisation of compounds}

\section{$1.1[\mathrm{A336}][\mathrm{V10}]$}

${ }^{1} \mathrm{H} \mathrm{NMR}\left(\mathrm{CDCl}_{3}, 400 \mathrm{MHz}\right) \delta: 3.40(3 \mathrm{H}, \mathrm{s}), 3.46(6 \mathrm{H}, \mathrm{m}), 1.63$ (broad), 1.26 (broad), 1.08 (3H, m), 0.88 (broad).

${ }^{13} \mathrm{C} \mathrm{NMR}\left(\mathrm{CDCl}_{3}, 100 \mathrm{MHz}\right) \delta: 182,61.0,48.8,31.6,29.0,26.3,22.5,22.3,14.0$.

Elemental analysis, calculated: C 77.85, H 13.63 and N 2.59; found: C 78.20, H 13.62 and N 2.38 .

\section{$1.2[\mathrm{A336}][\mathrm{C272}]$}

${ }^{1} \mathrm{H} \mathrm{NMR}\left(\mathrm{CDCl}_{3}, 400 \mathrm{MHz}\right) \delta: 3.35$ (3H, s), 3.44 (6H, m), 1.63 (broad), 1.26 (broad), $1.12(6 \mathrm{H}$, $\mathrm{m}), 0.91$ (broad).

${ }^{13} \mathrm{C} \mathrm{NMR}\left(\mathrm{CDCl}_{3}, 100 \mathrm{MHz}\right) \delta: 61.0,31.7,30.4,26.4,22.6,22.4,14.0$.

Elemental analysis, calculated: C 74.83, H 13.48 and N 2.13; found: C 75.50, H 13.35 and N 2.25 .

Note: The ${ }^{1} \mathrm{H}$ NMR and ${ }^{13} \mathrm{C}$ NMR spectra were not completely assigned due to the complexity of the spectra caused by the fact that these commercial extractants contain impurities and that Versatic acid 10 is a mixture of isomers. The ratio of [A336]/[V10] was calculated based on the shifts at $3.40 \mathrm{ppm}$ and $1.08 \mathrm{ppm}$ in Fig. S1, and the ratio of [A336]/[C272] was calculated based on the shifts at $3.35 \mathrm{ppm}$ and $1.12 \mathrm{ppm}$ in Fig. S3.

\subsection{Properties of [A336][V10]}

[A336][V10] and [A336][C272] were dried under vacuum in the Schlenk line under room temperature for 2 days. The dry [A336][C272] is a solid gel at room temperature $\left(22{ }^{\circ} \mathrm{C}\right)$, therefore its property was not further measured. The dry [A336][V10] is a viscous liquid. The water content of the dry [A336][V10] was determined to be $1.5 \mathrm{wt} \%$ by a Mettler-Toledo DL39 coulometric Karl Fischer titrator. It is difficult to further reduce water content because [A336][V10] is hygroscopic and heating is not applicable because quaternary ammonium is not thermally stable.

The density of [A336][V10] was determined to be $0.880 \mathrm{~g} \cdot \mathrm{cm}^{-3}$ (at $25^{\circ} \mathrm{C}$ ) using a density meter with an oscillating U-tube sensor (Anton Paar, DMA $4500 \mathrm{M}$ ). The viscosities of the dry [A336][V10] (containing about $1.5 \mathrm{wt} \%$ water) and diluted [A336][V10] solutions were measured using a rolling-ball type viscometer (Anton Paar, Lovis $2000 \mathrm{ME}$ ), and results are shown in Table S1. The dry [A336][V10] has a viscosity of $1413 \mathrm{mPa} \cdot \mathrm{s}$ at $25^{\circ} \mathrm{C}$, which is less viscous than Aliquat 336 that has a viscosity of $1500 \mathrm{mPa} \cdot \mathrm{s}$ at $30{ }^{\circ} \mathrm{C} .{ }^{1}$ The viscosity of [A336][V10] decreases quickly as it is diluted in $p$-cymene. The $60 \mathrm{vol} \%$ [A336][V10] diluted in $p$-cymene (about $1.0 \mathrm{~mol} \cdot \mathrm{L}^{-1}$ ) has a viscosity of $13.9 \mathrm{mPa} \cdot \mathrm{s}$ at $25{ }^{\circ} \mathrm{C}$, which is thin enough for the operation.

The solubility of [A336][V10] in water at room temperature $\left(22{ }^{\circ} \mathrm{C}\right)$ was estimated. $5 \mathrm{~mL}$ [A336][V10] and $5 \mathrm{~mL}$ water was mixed in a $15 \mathrm{~mL}$ centrifuge tube and shaken for one hour 
at $260 \mathrm{rpm}$ on a table shaker. Subsequently, the sample was stood still for overnight for phase separation and demulsification. The aqueous solution was then taken out and recorded for ${ }^{1} \mathrm{H}$ NMR spectra by a Bruker Avance 400 spectrometer operating at $400 \mathrm{MHz}$, with dimethylformamide as a reference. The solubility of [A336][V10] in water was estimated to be $0.21 \mathrm{~g} \cdot \mathrm{L}$ at $22{ }^{\circ} \mathrm{C}$, which is smaller than the solubility of Aliquat $336\left(1.2 \mathrm{~g} \cdot \mathrm{L}\right.$ at $\left.30{ }^{\circ} \mathrm{C}\right)$. The smaller solubility of [A336][V10] than Aliquat 336 is because that the [V10] anion is more hydrophobic than the $\mathrm{Cl}^{-}$anion in Aliquat 336. When diluted, the loss of [A336][V10] to the aqueous solution should be smaller. Besides, salts in the aqueous solution would reduce the solubility of [A336][V10]. Therefore, the loss of [A336][V10] to the aqueous solution should be negligible.

\section{Extraction of magnesium by [A336][V10]}

\subsection{Reduction of lithium co-extraction}

Several attempts were investigated to lower the co-extraction of lithium, including changing the O/A phase ratio, changing the magnesium concentration in the feed and changing the diluents. Changing the O/A phase ratio did not reduce the co-extraction of lithium, because the extraction of magnesium and lithium have the same trend with changing phase ratio (Fig. S5). The extraction of magnesium and lithium almost kept the same when diluents were changed (Fig. S6), hence not improving the separation either. Scrubbing the loaded organic led to a reduction of the lithium co-extraction (Fig. S7). A scrubbing experiment using different $\mathrm{MgCl}_{2}$ solutions was performed. It was found that about $62 \%$ of lithium was scrubbed, independently of the scrubbing solution. But the higher $\mathrm{MgCl}_{2}$ in the scrubbing solution, the smaller magnesium scrubbing. No magnesium would be scrubbed using a scrub solution of $106 \mathrm{~g} \mathrm{~L}^{-1}$ $\mathrm{Mg}$, but this scrubbing solution contained too much magnesium to be sent back to the feed solution, which would end up with no removal of magnesium. Decreasing the magnesium concentration of the scrub solutions led to an increase in the percentage scrubbing of magnesium. Up to $65 \%$ of the magnesium was scrubbed using a scrub solution containing $10 \mathrm{~g}$ $\mathrm{L}^{-1} \mathrm{Mg}$, which is too high. As a further attempt to reduce the co-extraction of lithium, different phase ratios were tested for scrubbing using $106 \mathrm{~g} \mathrm{~L}^{-1} \mathrm{Mg}$ (Figure S8). Unfortunately, increasing the scrubbing phase ratio $(\mathrm{O} / \mathrm{A})$ resulted in a decrease of the lithium scrubbing efficiency. Overall, scrubbing with $\mathrm{MgCl}_{2}$ did not improve $\mathrm{Mg} / \mathrm{Li}$ separation.

\subsection{Introducing $\mathrm{NaCl}$ into the scrubbing solution}

$\mathrm{NaCl}$ was further tested for scrubbing lithium from the organic phase, after the failure of scrubbing with $\mathrm{MgCl}_{2}$. The introduction of sodium into the system is not a problem since most brines already contain large amounts of sodium, and the separation of sodium and lithium is easy. First, a solution with $106 \mathrm{~g} \mathrm{~L}^{-1} \mathrm{Mg}$ and saturated with $\mathrm{NaCl}$ was used, to investigate the possibility of replacing lithium extraction by sodium. No magnesium was scrubbed, whereas 93\% of lithium could be scrubbed. Introducing sodium in the scrubbing solution increased the scrubbing of lithium. Secondly, a scrubbing solution composed of $\mathrm{NaCl}\left(360\right.$ and $\left.180 \mathrm{~g} \mathrm{~L}^{-1}\right)$ or $\mathrm{KCl}$ (254 and $127 \mathrm{~g} \mathrm{~L}^{-1}$ ) was investigated (Fig. S9). Scrubbing solutions containing various concentrations of $\mathrm{NaCl}$ or $\mathrm{KCl}$ showed 50 to $70 \%$ magnesium scrubbing. Saturated $\mathrm{NaCl}$ (360 
$\mathrm{g} \mathrm{L}^{-1}, 20^{\circ} \mathrm{C}$ ) showed less magnesium scrubbing (55\%) compared to a $180 \mathrm{~g} \mathrm{~L}^{-1} \mathrm{NaCl}$ scrubbing solution. The same trend was observed for a $\mathrm{KCl}$ scrubbing solution. A reason for the high percentage scrubbing of magnesium is because the chloride concentration in the scrub solution was not high enough. More than $95 \%$ of the co-extracted lithium was scrubbed with these solutions. In short, $\mathrm{NaCl}$ and $\mathrm{KCl}$ are effective for scrubbing of lithium, but the scrubbing of magnesium is still too high. 

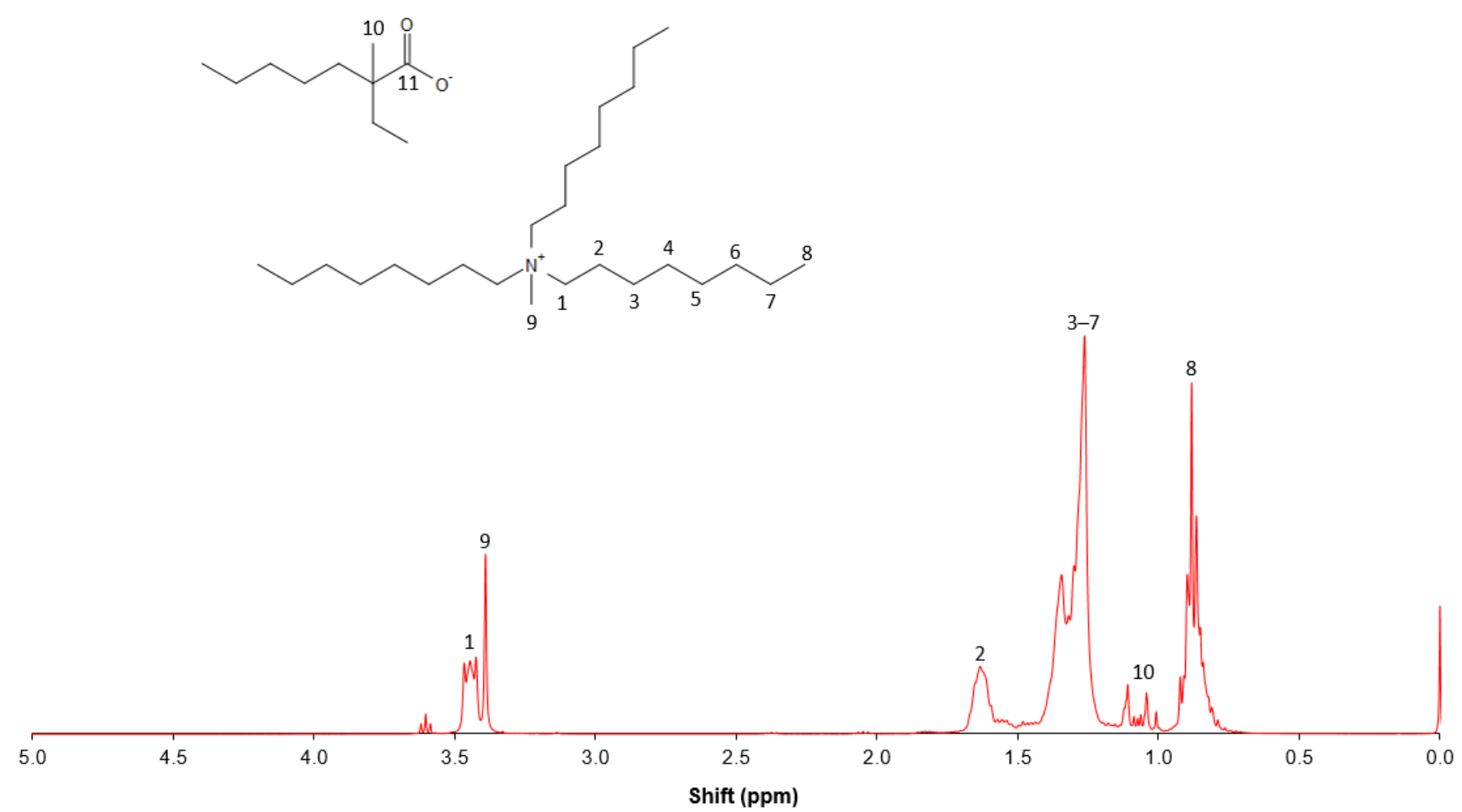

Figure S1 ${ }^{1} \mathrm{H}$ NMR spectrum of [A336][V10] dissolved in $\mathrm{CDCl}_{3}$. The main component of A336 is shown together with one possible isomer of V10. The ratio of [A336] ${ }^{+}$and [V10] ${ }^{-}$was calculated based on the integral of protons at positions 9 and 10. 


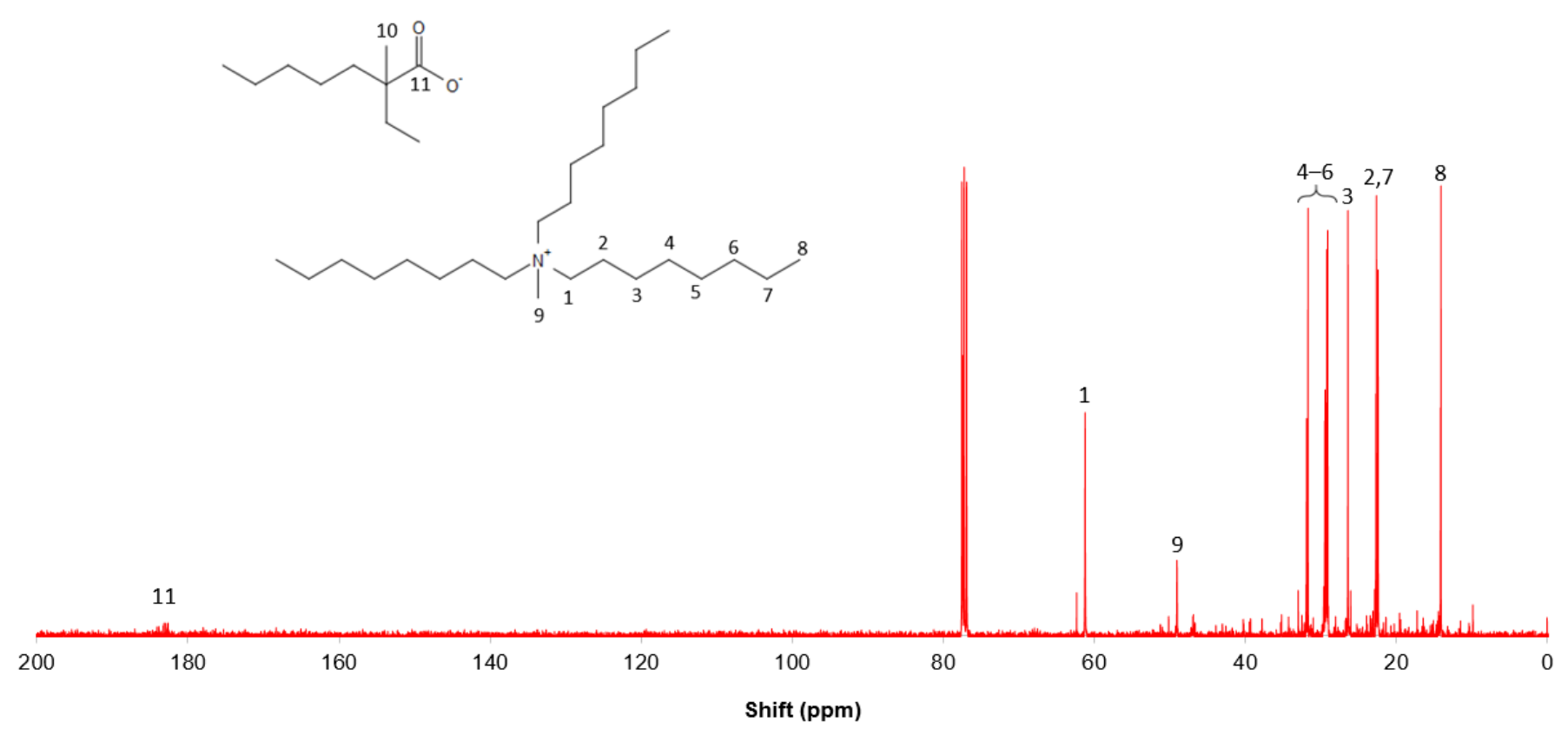

Figure S2 ${ }^{13} \mathrm{C}$ NMR spectrum of [A336][V10] dissolved in $\mathrm{CDCl}_{3}$. 


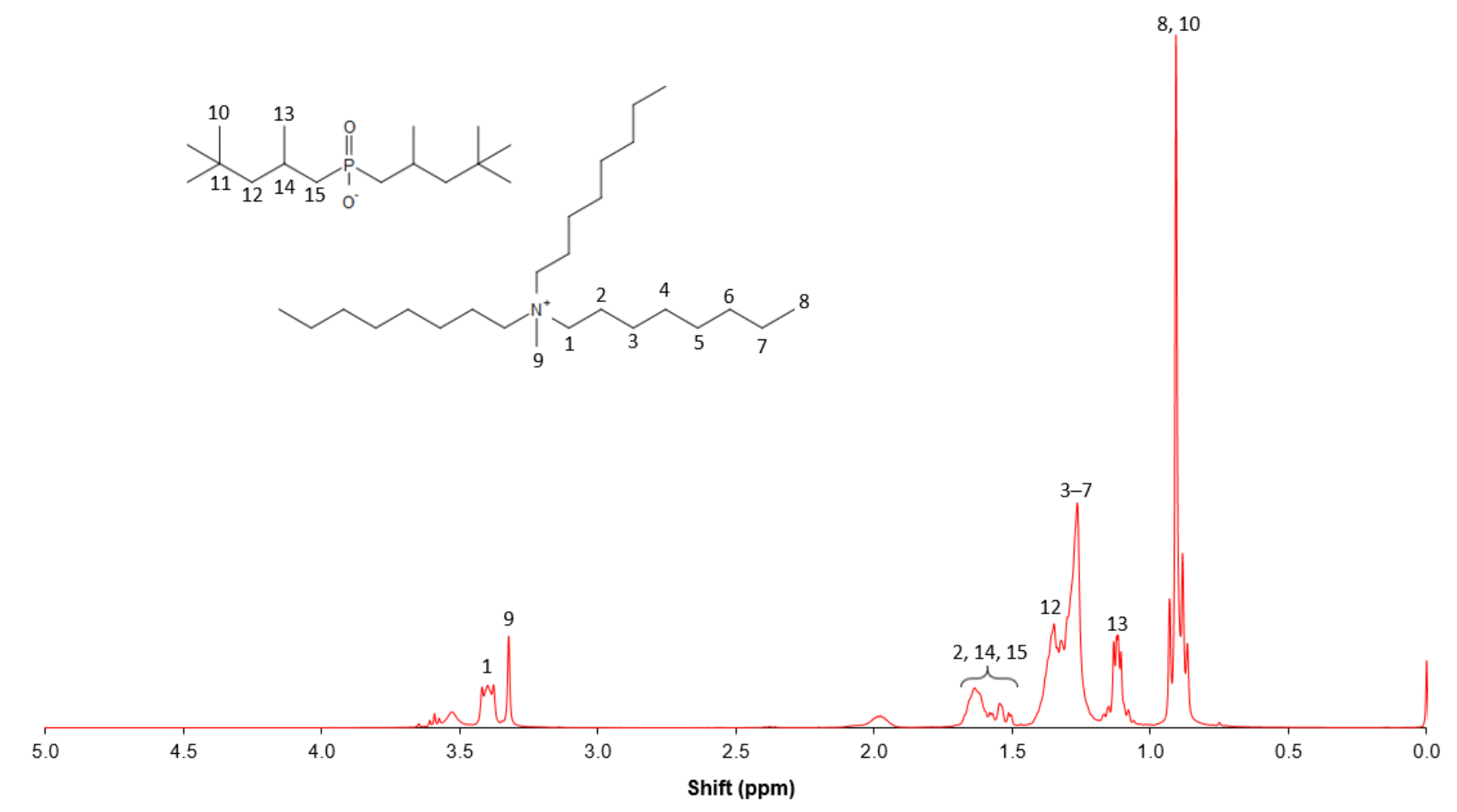

Figure S3 ${ }^{1} \mathrm{H}$ NMR spectrum of [A336][C272] dissolved in $\mathrm{CDCl}_{3}$. The main component of A336 is shown, together with the main component of C272. The ratio of $[\mathrm{A} 336]^{+}$and $[\mathrm{C} 272]^{-}$was calculated based on the integral of protons at positions 9 and 13. 


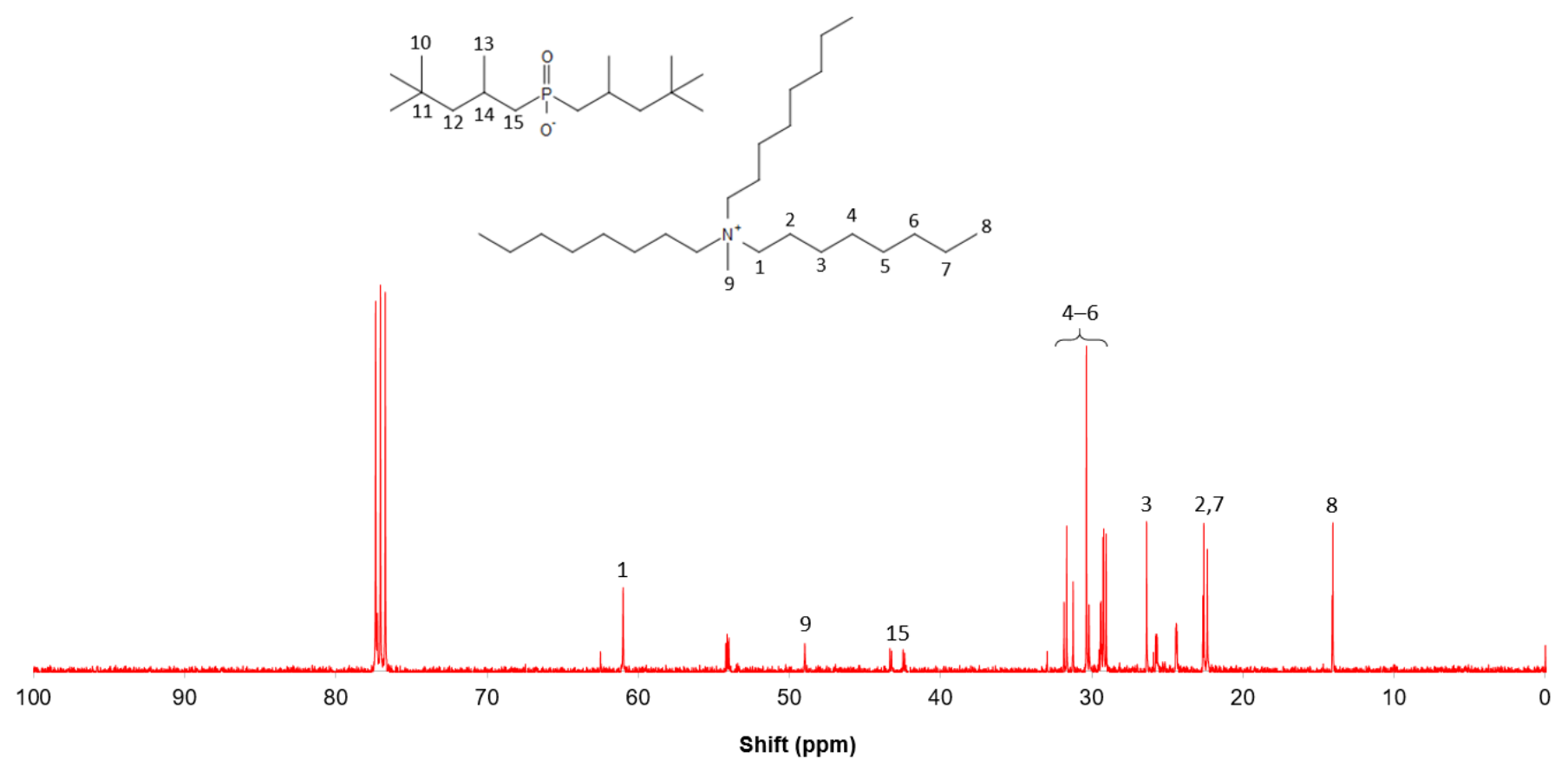

Figure S4 ${ }^{13} \mathrm{C}$ NMR spectrum of [A336][C272] dissolved in $\mathrm{CDCl}_{3}$. 


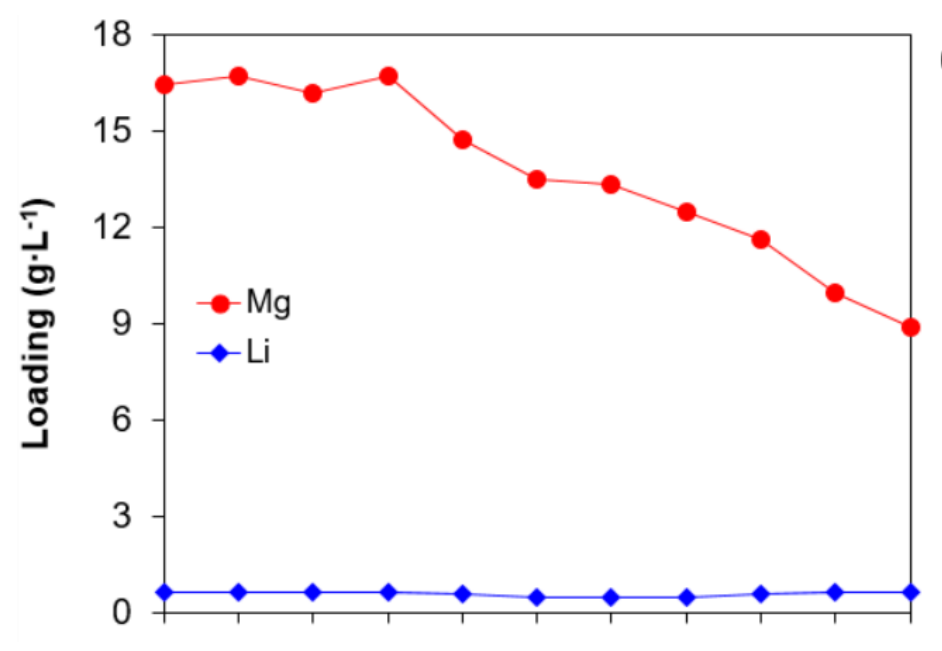

(a)

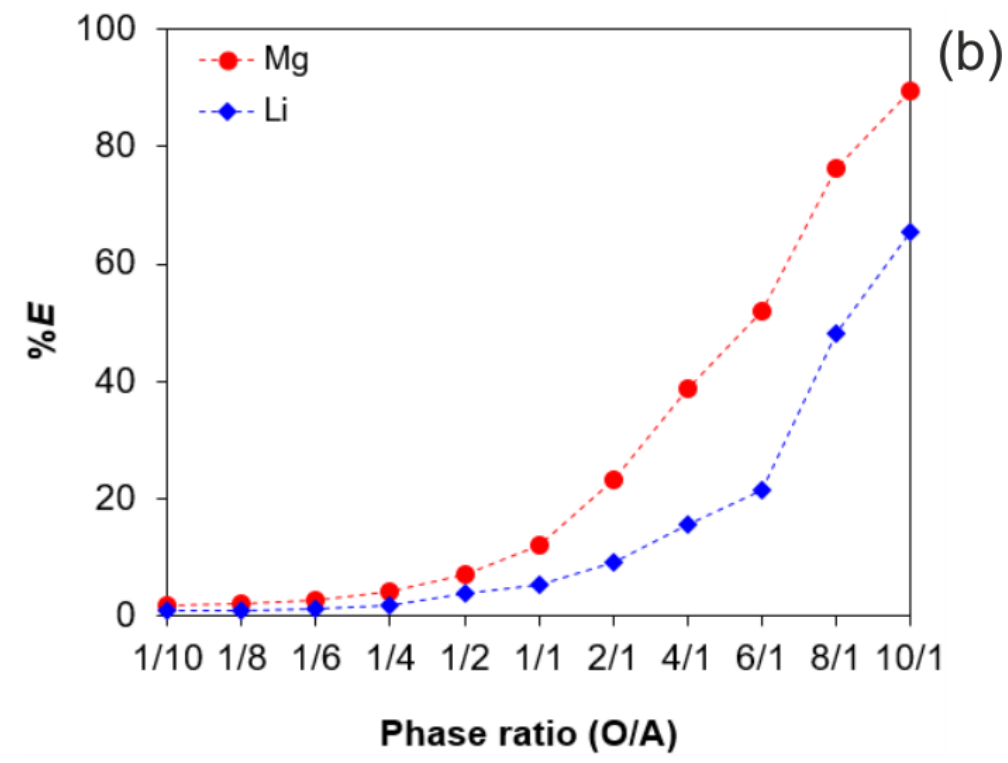

Figure S5 Effect of varying phase ratio on the loading (a) and the percentage extraction (b) of magnesium and lithium using $1.0 \mathrm{~mol} \mathrm{~L}^{-1}$ [A336][V10] in $p$-cymene. 


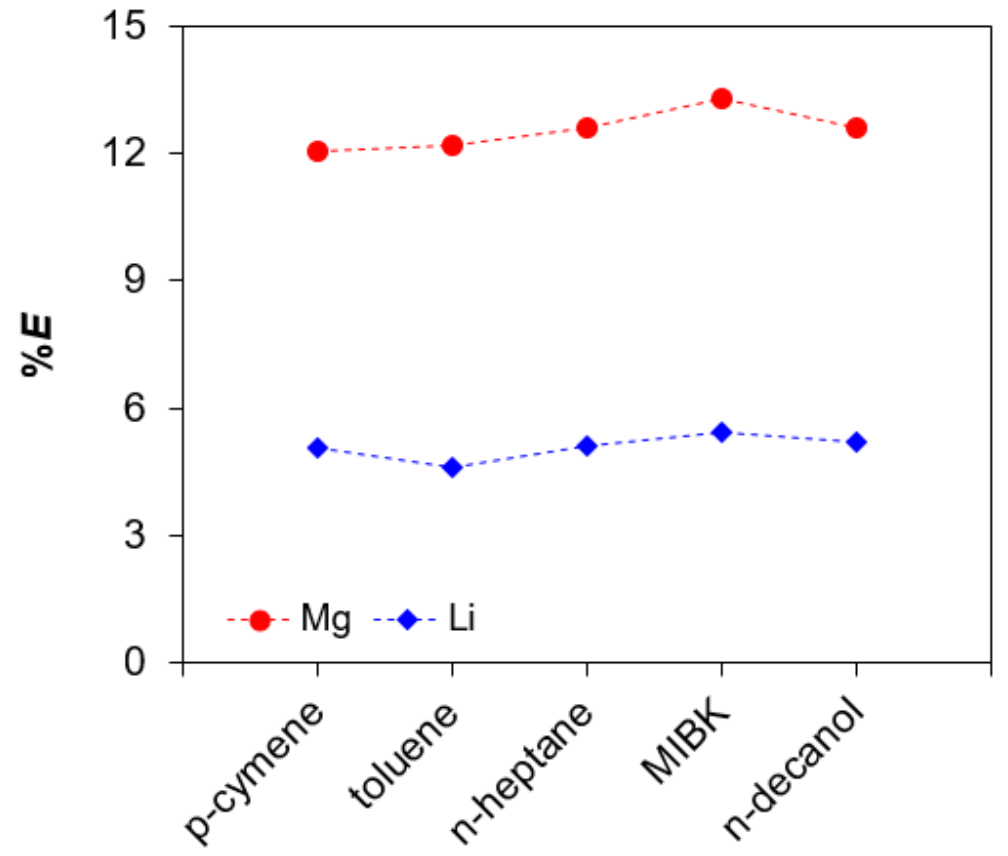

Figure S6 Percentage extraction of magnesium and lithium when using $1.0 \mathrm{~mol} \mathrm{~L}^{-1}$ [A336][V10] in different diluents. The phase ratio was 1/1. 


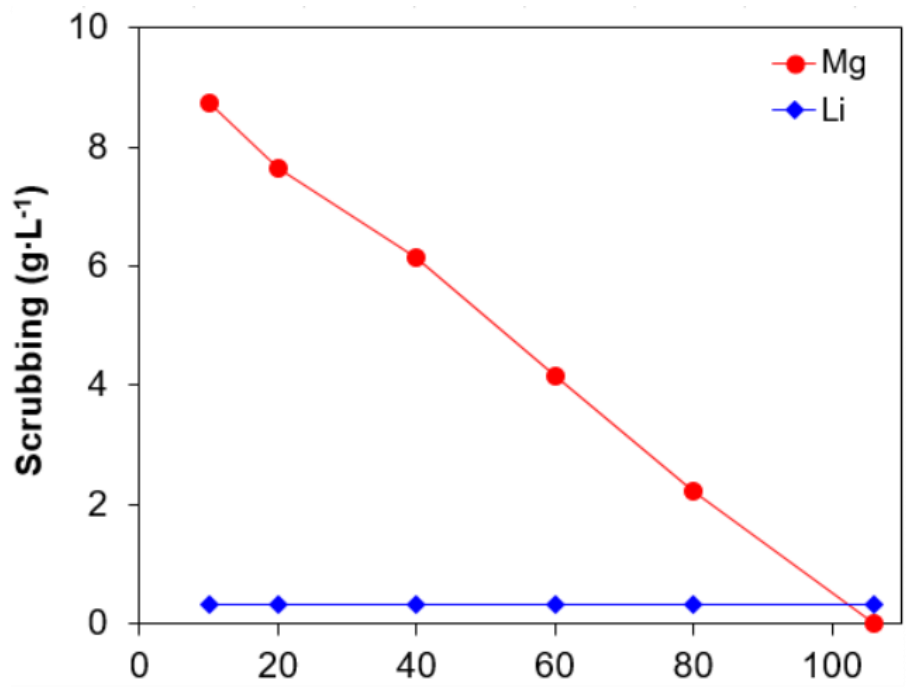

(a)

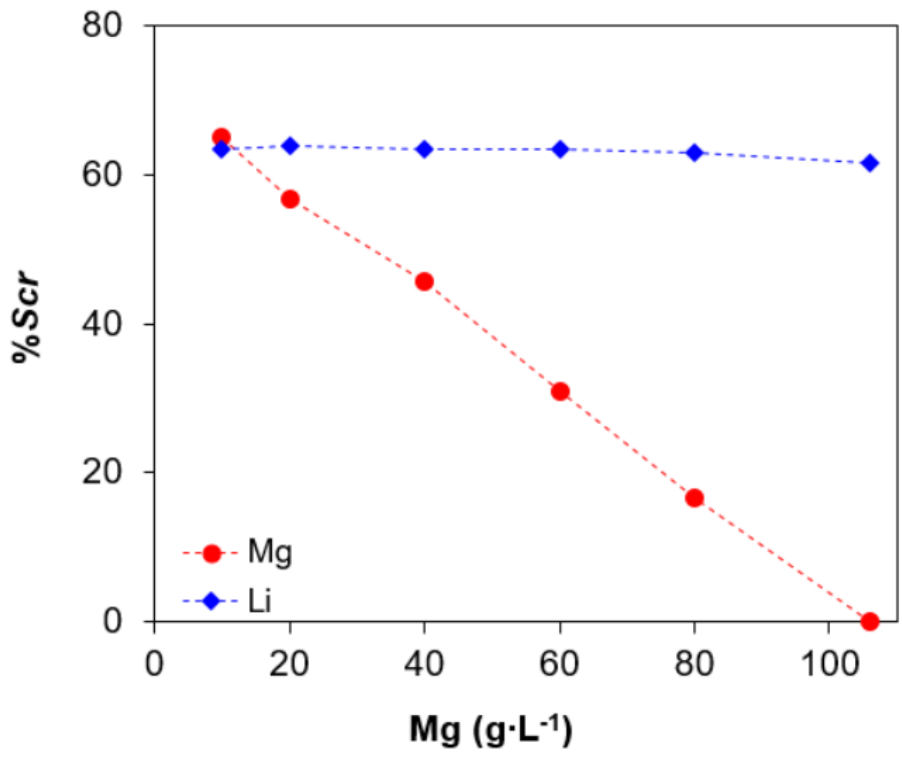

(b)

and percentage (b) scrubbed. 


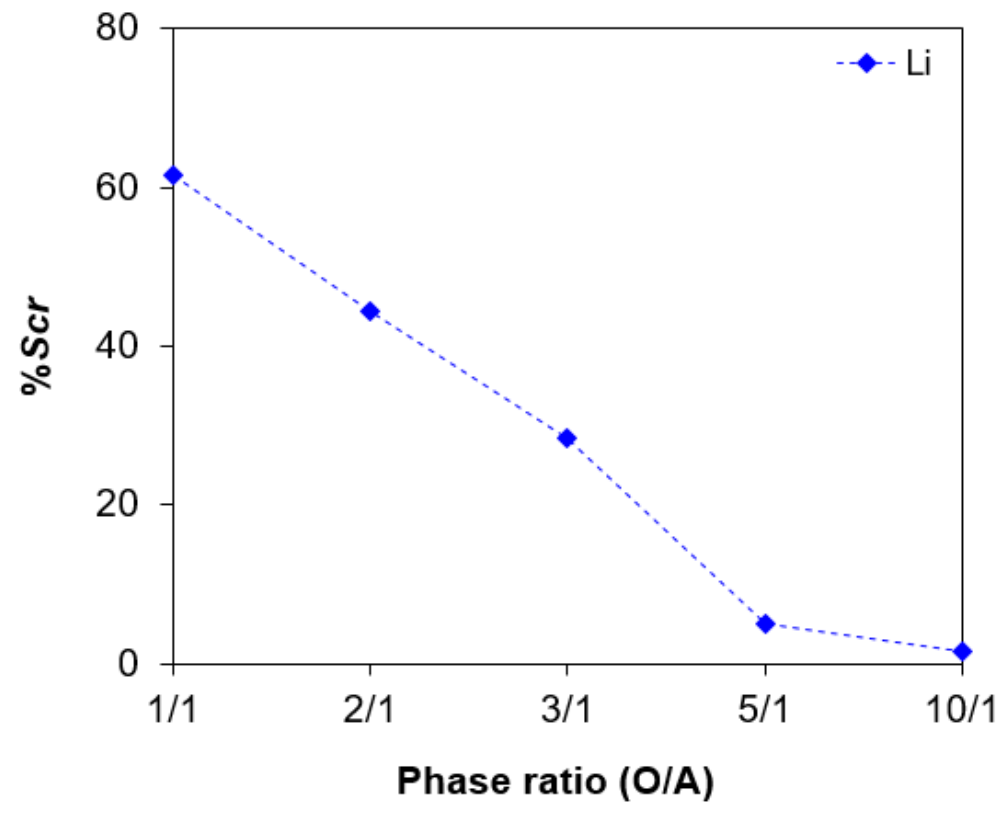

Figure S8 Scrubbing of lithium via variation of phase ratio to reduce consumption of the scrubbing solution (106 $\mathrm{g} \mathrm{L}^{-1} \mathrm{Mg}$ ). 


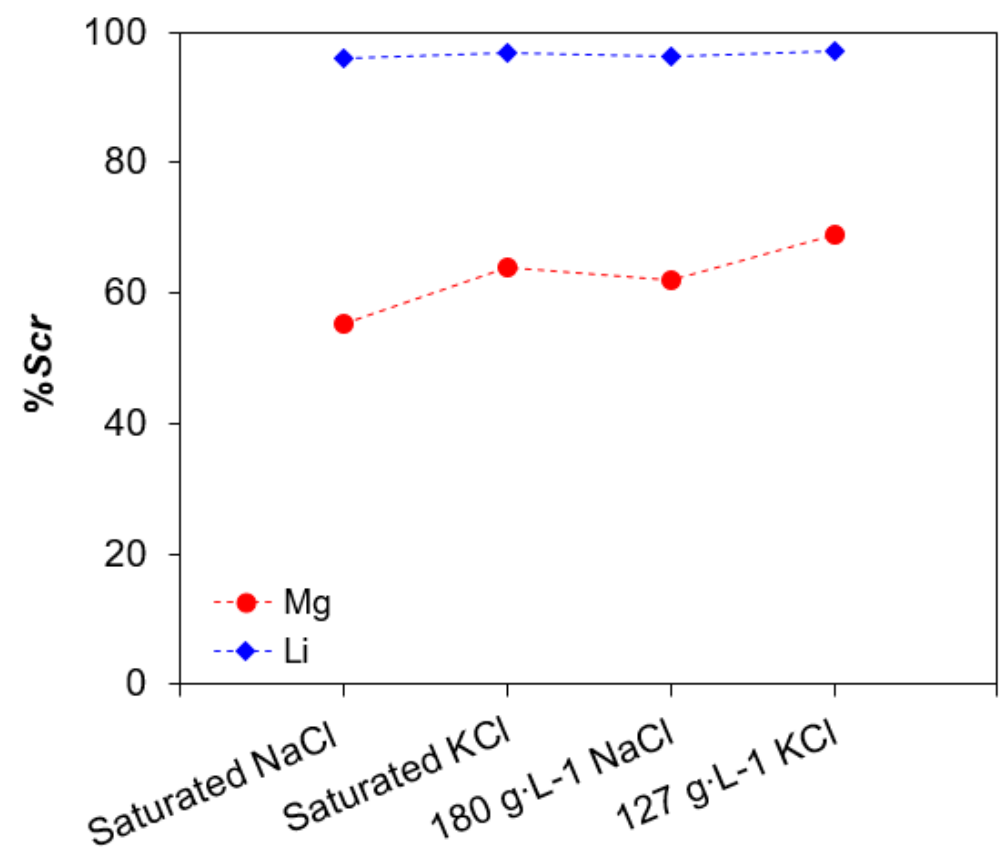

Figure S9 Percentage scrubbing of magnesium and lithium using different scrub solutions. 


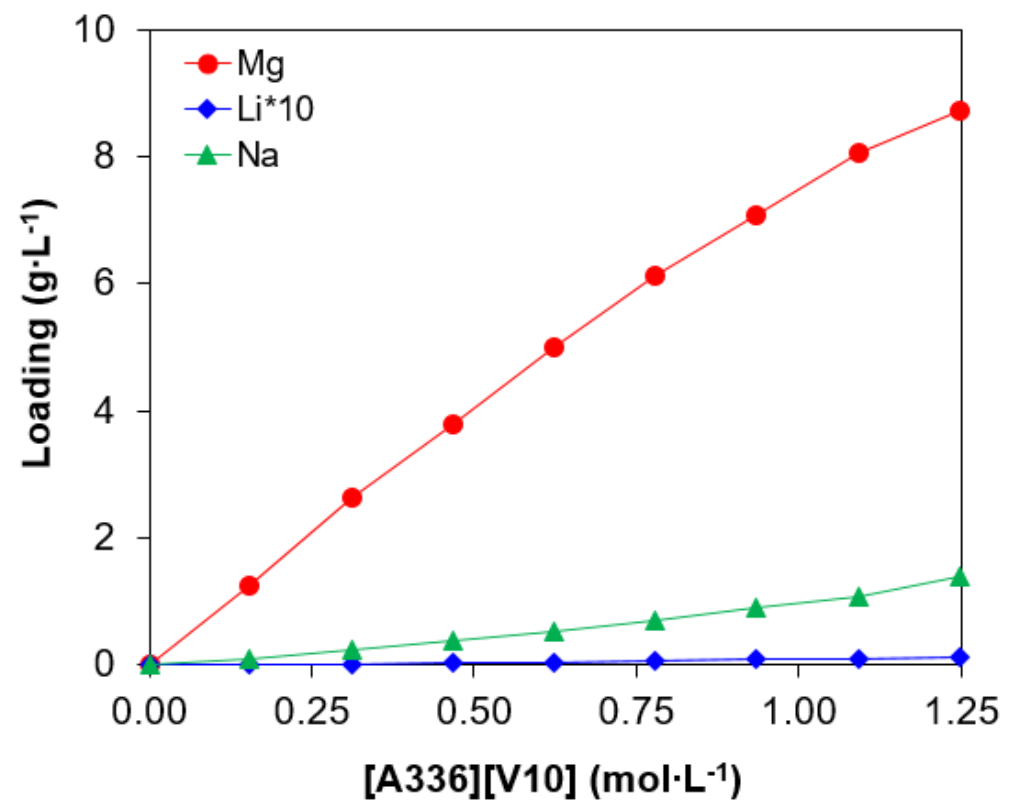

Figure S10 Loading of magnesium, lithium $(* 10)$ and sodium using [A336][V10] in $p$-cymene from the original brine $\left(15 \mathrm{~g} \mathrm{~L}^{-1} \mathrm{Mg}, 0.2 \mathrm{~g} \mathrm{~L}^{-1} \mathrm{Li}\right.$ and $\left.80 \mathrm{~g} \mathrm{~L}^{-1} \mathrm{Na}\right)$. 


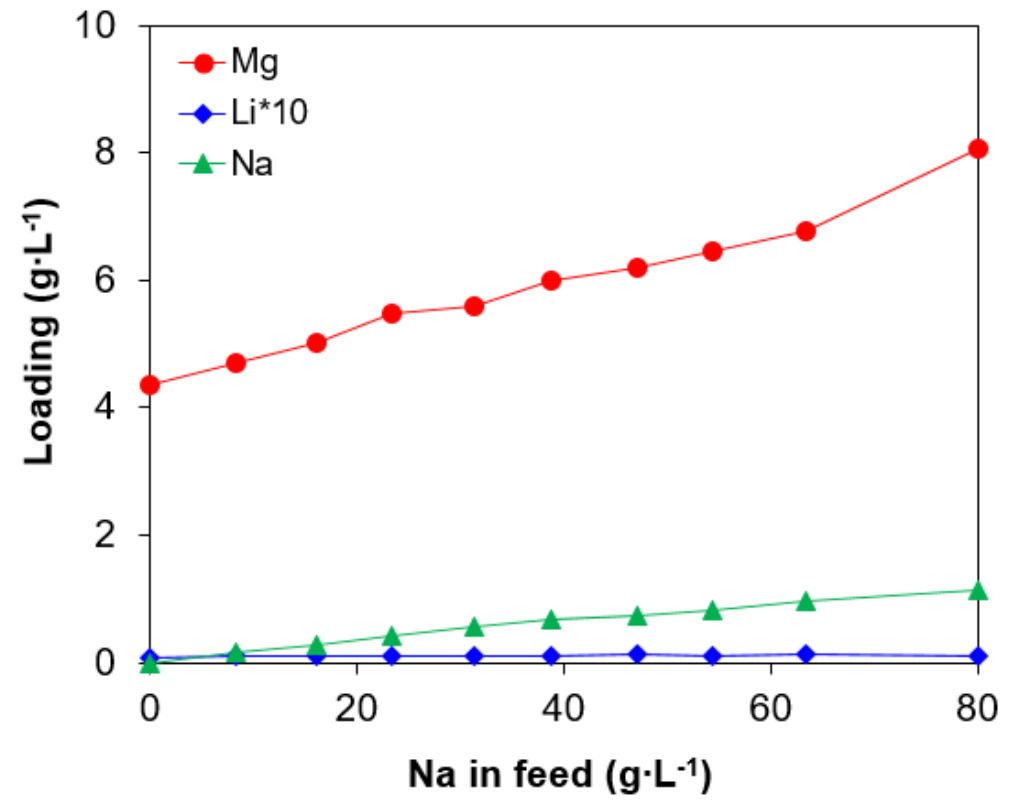

Figure S11 Loading of magnesium, lithium, and sodium from feed solutions containing $15 \mathrm{~g}$ $\mathrm{L}^{-1} \mathrm{Mg}$ and $0.2 \mathrm{~g} \mathrm{~L}^{-1} \mathrm{Li}$ and various $\mathrm{Na}$. 

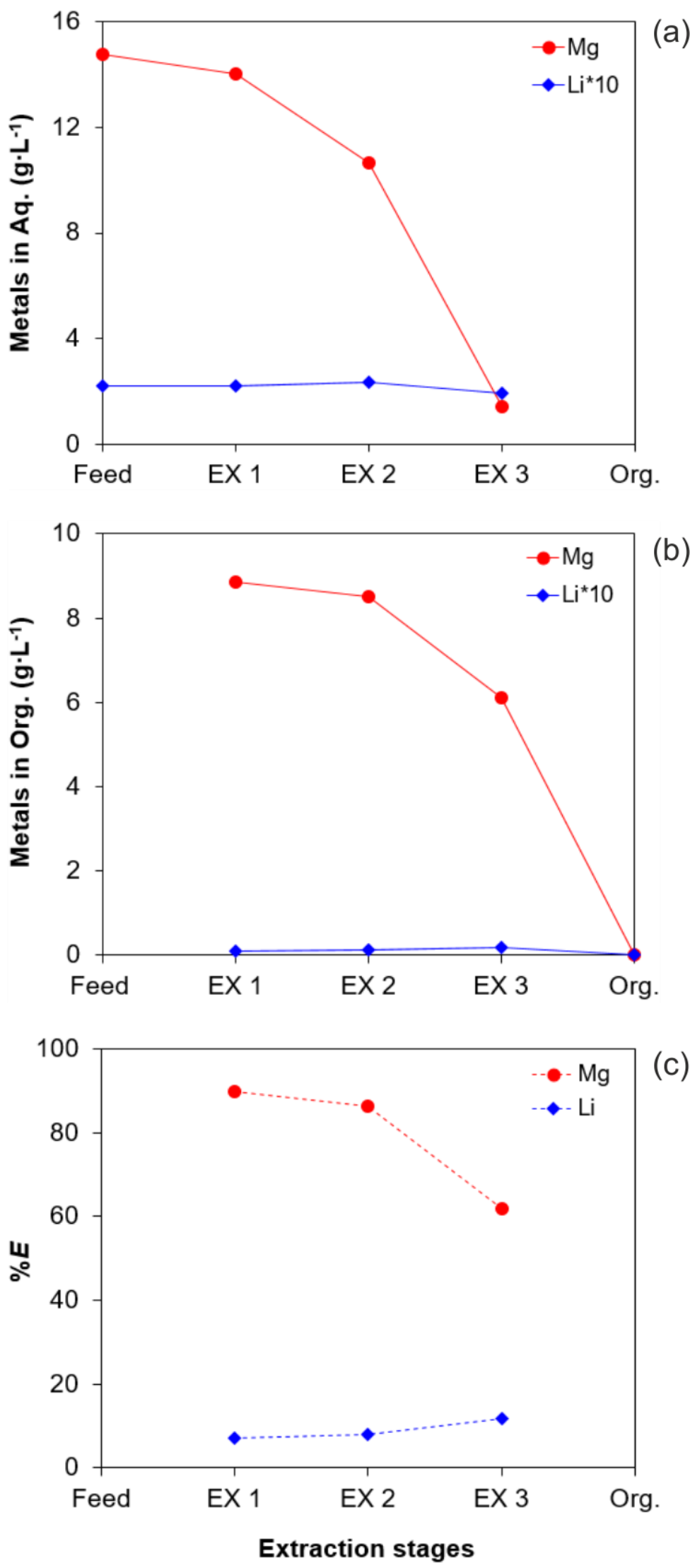

Figure S12 Metal loading profiles of magnesium and lithium in the aqueous phase (a) and in the organic phase (b), and percentage extraction of magnesium and lithium relative to the feed solution (c), during the three-stage batch counter current test. Phase ratio O/A was 1.5/1. 


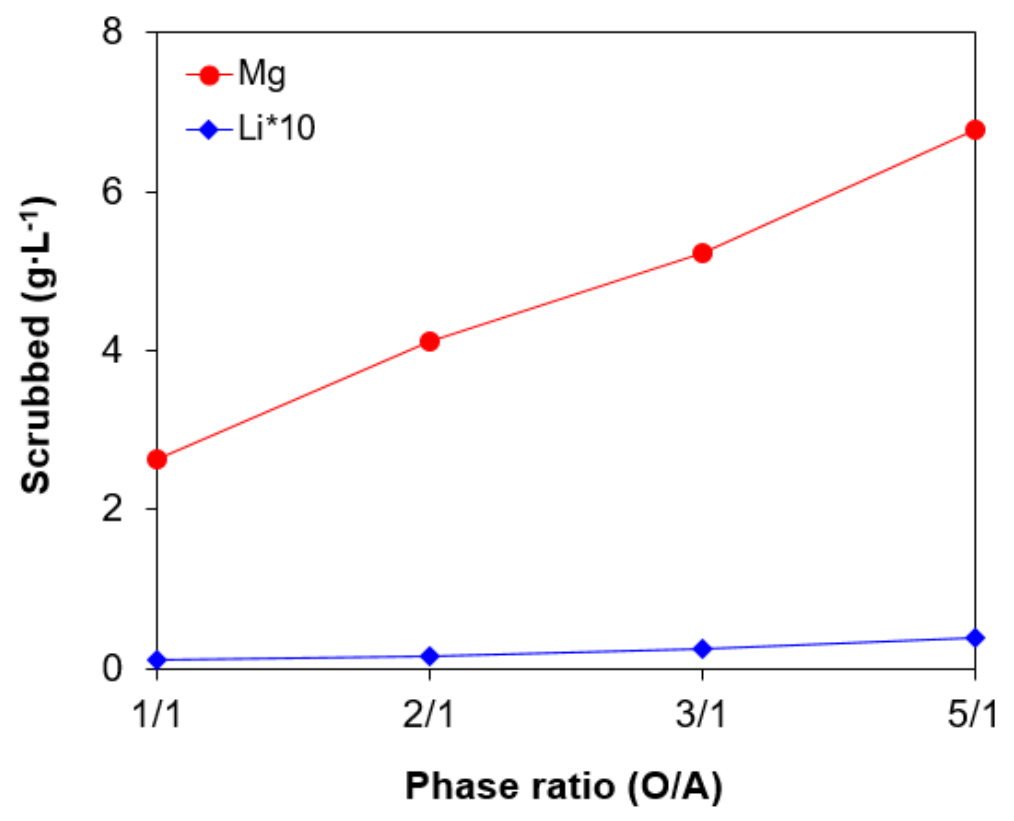

Figure S13. Amounts of lithium and magnesium scrubbed (concentration in the resultant aqueous solution) in terms of the phase ratio, using an $80 \mathrm{~g} \mathrm{~L}^{-1} \mathrm{Na}$ scrubbing solution. 


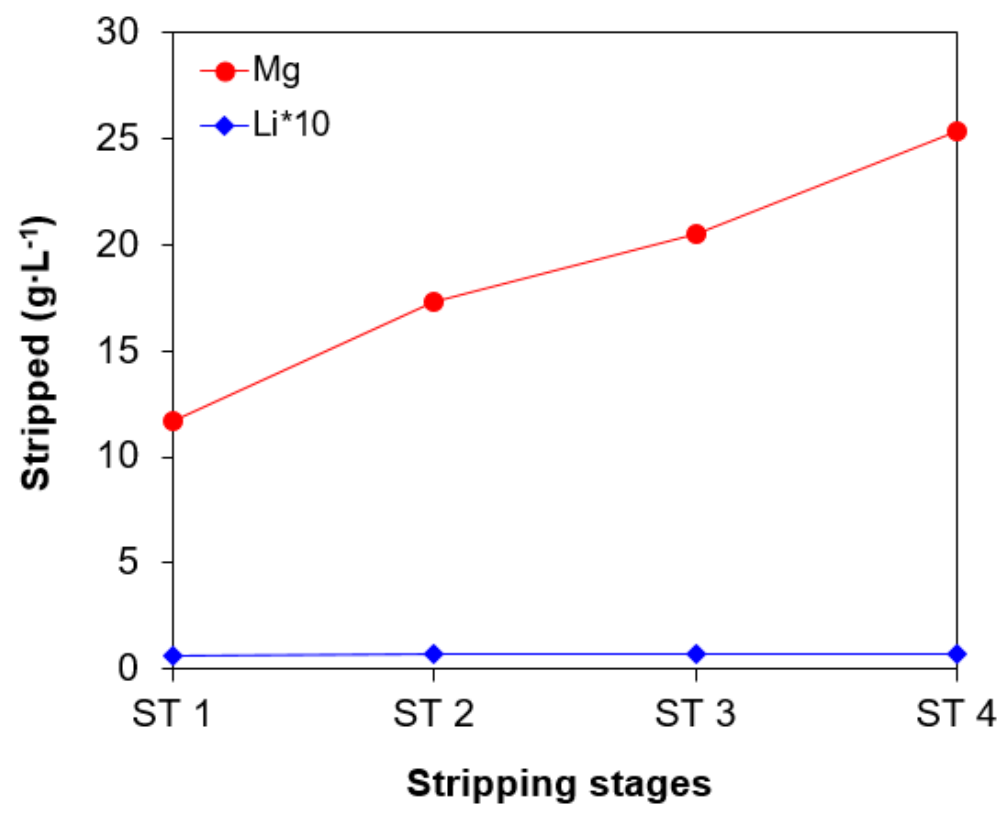

Figure S14. Accumulative amounts of magnesium and lithium stripped (concentration in the resultant aqueous solution) by water (ST 1, ST 2 and ST 3) and $1 \mathrm{~mol} \mathrm{~L}^{-1} \mathrm{HCl}$ (ST 4) with an O/A phase ratio of $3 / 1$. 

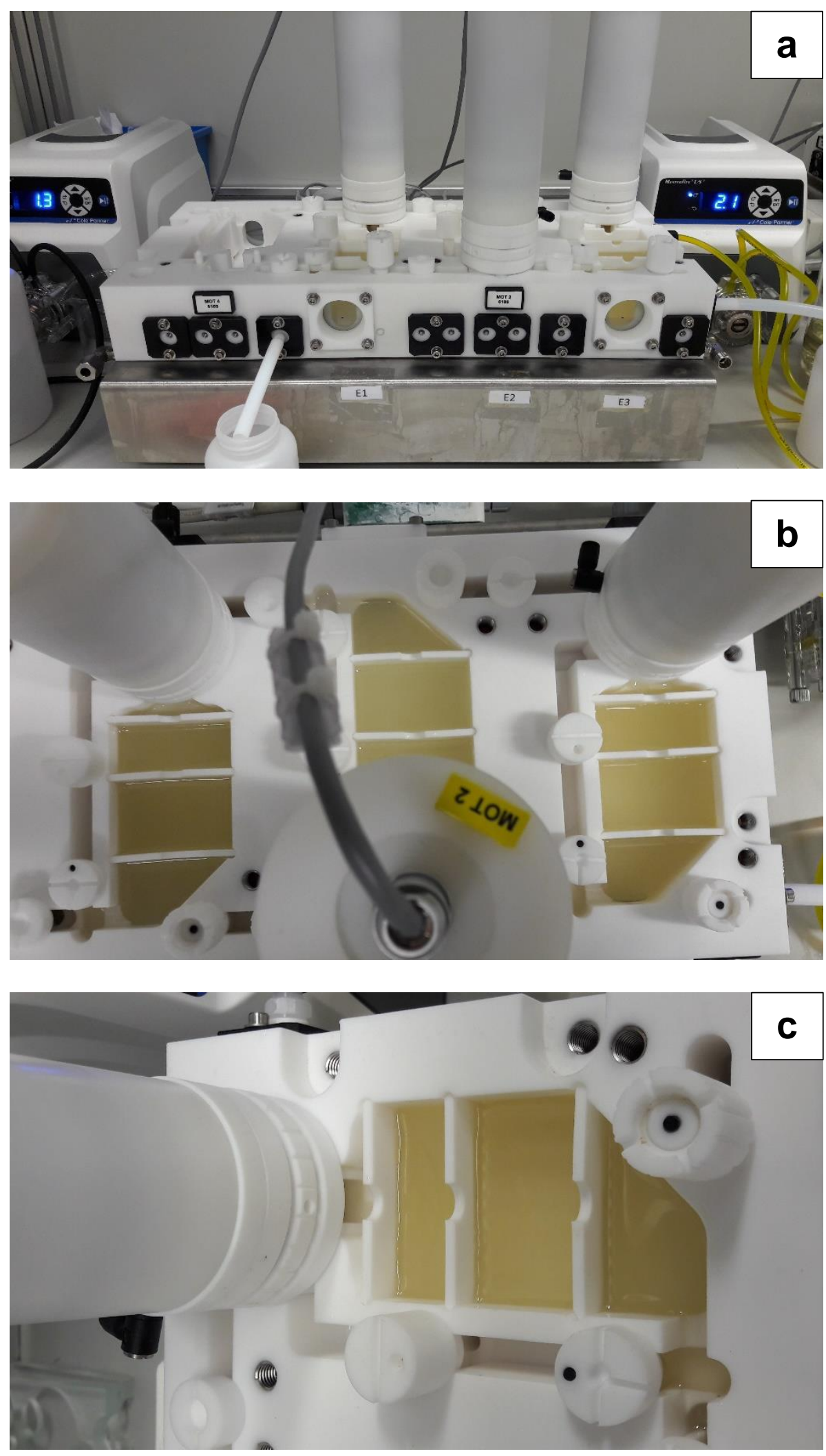

Figure S15. Pictures of the mixer-settler set-up: the side view (a) and the top view (b) of the three-stage mixer-settler battery and the top view of the EX 3 (c). 

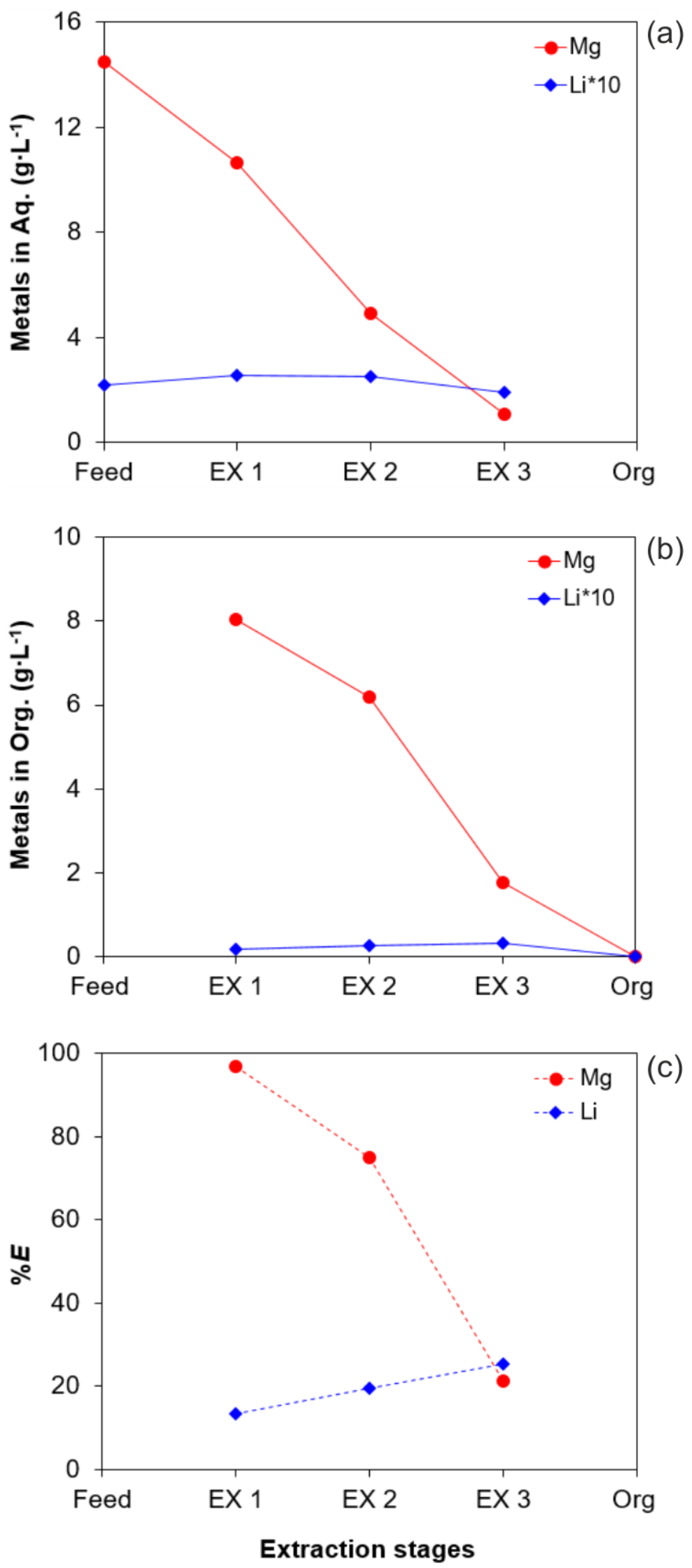

Figure S16 Metal loading profile of magnesium and lithium in the aqueous phase (a) and in the organic phase (b), and percentage extraction of magnesium and lithium relative to the feed solution (c), during the three-stage mixer-settler test at the $15^{\text {th }}$ hour. Phase ratio O/A was 1.7/1. 

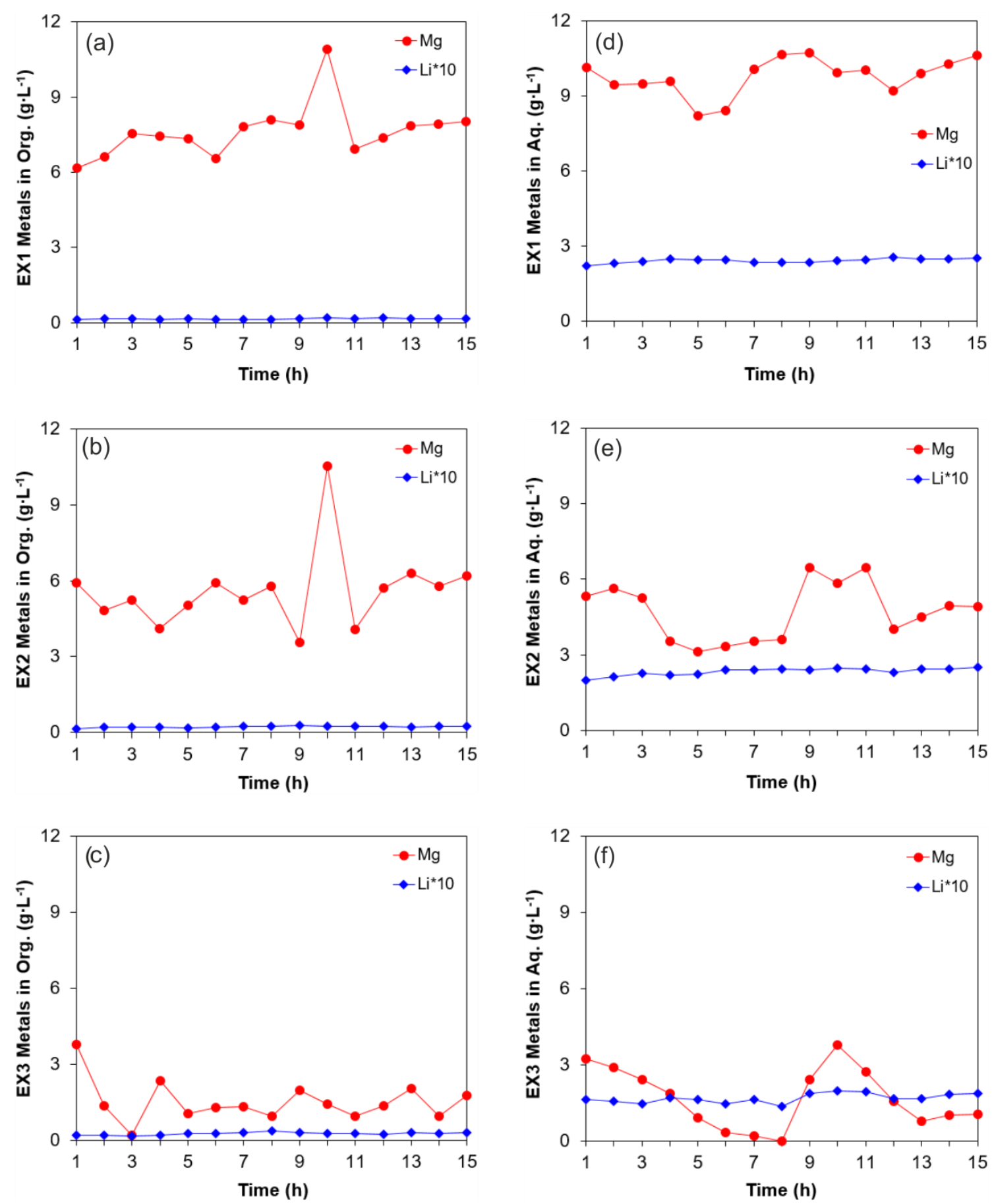

Figure S17. Metal loading profiles of magnesium and lithium in the aqueous and the organic phase as a function of time during the three-stage mixer-settler test, phase ratio $\mathrm{O} / \mathrm{A}=1.7 / 1$. Notes: (1) The test was stopped after running for 7 hours; the test was re-started the next day. (2) The fluctuation of metal concentration at the $10^{\text {th }}$ hour was probably caused by the disturbance of the extraction system due to taking samples. 
Table S1. Viscosity and density of [A336][V10]

\begin{tabular}{ccccc}
\hline \multirow{2}{*}{ Temperature $\left({ }^{\circ} \mathrm{C}\right)$} & \multicolumn{2}{c}{ Sample Composition $($ vol\%) } & \multirow{2}{*}{ Viscosity $(\mathrm{mPa} \cdot \mathrm{s})$} & density $\left(\mathrm{g} \cdot \mathrm{cm}^{-3}\right)$ \\
\cline { 2 - 3 } & {$[\mathrm{A} 336][\mathrm{V} 10]$} & $p$-cymene & & - \\
\hline 50 & 100 & 0 & 208.3 & 0.880 \\
25 & 100 & 0 & 1143.0 & - \\
25 & 80 & 20 & 84.5 & - \\
25 & 60 & 40 & 13.9 & - \\
25 & 40 & 60 & 7.0 & - \\
25 & 20 & 80 & 2.7 & - \\
\hline
\end{tabular}




\section{Reference}

1. BASF. Technical Information: Aliquat 336 (Report No. TI/EVH 0125/4 e). September 2015. 